\title{
Enhanced Adsorption Selectivity of Hydrogen/Methane Mixtures in Metal-Organic Frameworks with Interpenetration: A Molecular Simulation Study
}

\author{
Bei Liu, ${ }^{\dagger}$ Qingyuan Yang, ${ }^{\ddagger}$ Chunyu Xue, ${ }^{\ddagger}$ Chongli Zhong, ${ }^{*}, *$ Biaohua Chen, ${ }^{\ddagger}$ and Berend Smit ${ }^{\S}$ \\ Van't Hoff Institute for Molecular Sciences, University of Amsterdam, Nieuwe Achtergracht 166, \\ 1018 WV Amsterdam, The Netherlands, Department of Chemical Engineering, Beijing University of Chemical \\ Technology, Beijing 100029, China, and Department of Chemical Engineering, University of California, \\ Berkeley, California 94720
}

Received: March 18, 2008; Revised Manuscript Received: April 18, 2008

\begin{abstract}
In this work a systematic molecular simulation study was performed to study the effect of interpenetration on gas mixture separation in metal-organic frameworks (MOFs). To do this, three pairs of isoreticular MOFs (IRMOFs) with and without interpenetration were adopted to compare their adsorption separation selectivity for $\mathrm{CH}_{4} / \mathrm{H}_{2}$ mixtures at room temperature. The results show that methane selectivity is greatly enhanced in the interpenetrated IRMOFs compared with their noninterpenetrated counterparts, due to the formation of additional small pores and adsorption sites by the interpenetration of frameworks. Furthermore, this work shows methane selectivity behavior is more complex in the former and selectivity differs largely in the different areas of the pores, attributed to the existence of various small pores of different sizes. In addition, the present work shows the ideal adsorbed solution theory is likely to be applicable to interpenetrated MOFs with complex structures.
\end{abstract}

\section{Introduction}

Metal-organic frameworks (MOFs) are a family of hybrid porous materials that are formed by the coordination of metal ions with organic linkers. These materials feature opportunities for functionality and structure by a rational combination of different metal ions with different organic linkers. To date a large number of different MOFs have been synthesized which have shown various promising applications in, for example, gas storage, separation, or catalysis, etc. ${ }^{1-3}$ According to the structural characteristics, they can be categorized into two types: those with noninterpenetrated frameworks ${ }^{4,5}$ and those with interpenetrated ones. ${ }^{6,7}$ In the latter additional small pores and adsorption sites are formed by the interpenetration of frameworks, leading to MOFs with multipores of different sizes that may exhibit enhanced gas adsorption and separation properties. ${ }^{7-13}$

Currently, most theoretical ${ }^{14-23}$ and experimental ${ }^{24-26}$ investigations focus on noninterpenetrated MOFs and far less attention has been paid on these interpenetrated structures. Extensive studies have been carried out on the adsorption and diffusion of pure gases in MOFs, ${ }^{1-6,8-10,14-18,24-29}$ but far less attention has been given to the separation of gas mixtures. ${ }^{711-13,19-23}$ Among the available separation studies, Chen and co-workers performed experimental separations of light gas mixtures in several interpenetrated MOFs that exhibit high selectivity. $7,11,12$ These experimental results encouraged us to carry out a systematic study on the effect of interpenetration (catenation) on gas mixture separations. In this work, we have selected three pairs of MOFs, ${ }^{30}$ three interpenetrated MOFs and their noninterpenetrated counterparts, which allows us to compare the effect of interpenetration while excluding the influences of the differences in chemical composition of these materials. We

\footnotetext{
* Corresponding author. E-mail: zhongcl@mail.buct.edu.cn.

$\dagger$ University of Amsterdam.

$\$$ Beijing University of Chemical Technology.

$\S$ University of California, Berkeley.
}

selected the $\mathrm{CH}_{4} / \mathrm{H}_{2}$ system as the model mixture to separate since this is an important practical system that is involved in the process of purification of synthetic gas obtained from steam reforming of natural gas. Currently, 95\% of hydrogen used in fuel cells is produced by this method, and components such as methane must be removed from the synthetic gas before hydrogen can be used effectively. ${ }^{31}$

\section{Models and Computational Method}

2.1. MOF Structures. In this work, six isoreticular metalorganic frameworks (IRMOFs), as synthesized by Eddaoudi et al., ${ }^{30}$ were adopted as representatives of MOFs. The crystal structures of these IRMOFs were constructed from the XRD data $^{30}$ using Materials Studio Visualizer ${ }^{32}$ (see Figure 1).

As shown in Figure 1, IRMOFs-10, -12, and -14 feature the same primitive cubic topology with the octahedral $\mathrm{Zn}_{4} \mathrm{O}\left(\mathrm{CO}_{2}\right)$ clusters linked by different organic dicarboxylate linkers, whereas IRMOFs-9, -11 , and -13 are the interpenetrated counterparts of IRMOFs-10, -12, and -14, respectively. The structural properties for these IRMOF materials are summarized in Table 1, where the free volumes were calculated using a probe size of $0.0 \AA$ to determine the total free volume not occupied by the framework atoms. It should be noted that this method of calculating free volume, as done by others, ${ }^{14,27}$ is based solely on the system geometry.

2.2. Force Fields. In the present work, a single LennardJones (LJ) interaction site model was used to describe a methane molecule, and the potential parameters were taken from the TraPPE force field. ${ }^{33} \mathrm{H}_{2}$ was modeled as a rigid diatomic molecule with bond length of $0.74 \AA$, and each atom $\mathrm{H}$ was represented as an LJ interaction site with the potential parameters taken from our previous work. ${ }^{34}$ Electrostatic interactions were not included, as previous simulations have shown that the effect of these interactions on the adsorption of hydrogen in MOFs is very small at room temperature. ${ }^{35}$ The above potential models have been successfully used to model the adsorptions of methane 


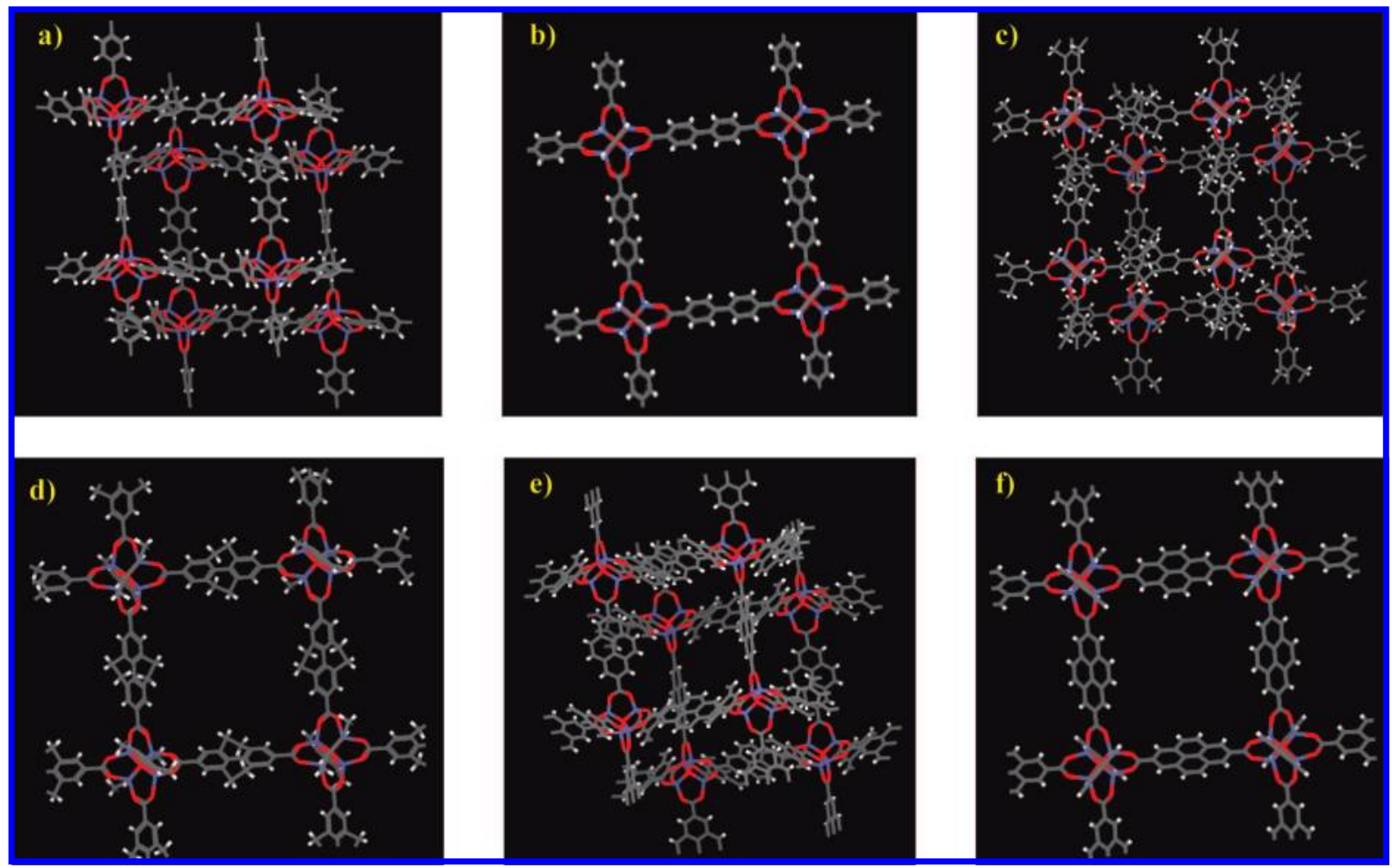

Figure 1. Crystal structures of the IRMOFs used in the simulation: (a) IRMOF-9, (b) IRMOF-10, (c) IRMOF-11, (d) IRMOF-12, (e) IRMOF-13, (f) IRMOF-14 (Zn, blue; O, red; C, gray, and $\mathrm{H}$, white).

TABLE 1: Structural Properties for the IRMOFs Studied in This Work

\begin{tabular}{|c|c|c|c|c|c|c|c|}
\hline material & pore shape ${ }^{a}$ & unit cell $(\AA)$ & cell angle (deg) & $d_{\text {pore }}(\AA)^{a}$ & $\begin{array}{c}\rho_{\text {crys }} \\
\left(\mathrm{g} / \mathrm{cm}^{3}\right)^{a}\end{array}$ & $\begin{array}{c}V_{\text {free }} \\
\left(\mathrm{cm}^{3} / \mathrm{g}\right)^{b}\end{array}$ & $\begin{array}{c}\text { porosity } \\
(\%)^{b}\end{array}$ \\
\hline IRMOF-10 & cubic & $a=b=c=34.281$ & $\alpha=\beta=\gamma=90$ & $16.7 / 20.2$ & 0.33 & 2.66 & 87.9 \\
\hline IRMOF-12 & cubic & $a=b=c=34.281$ & $\alpha=\beta=\gamma=90$ & $13.9 / 20.0$ & 0.38 & 2.24 & 85.1 \\
\hline IRMOF-9 & cubic/catenation & $a=17.147, b=23.322, c=25.255$ & $\alpha=\beta=\gamma=90$ & $4.5 / 6.3 / 8.1 / 10.7$ & 0.66 & 1.14 & 74.8 \\
\hline IRMOF-11 & cubic/catenation & $a=b=24.822, c=56.734$ & $\alpha=\beta=90, \gamma=120$ & 3.5/3.8/4.7/6.1/7.3/11.1 & 0.76 & 0.92 & 69.8 \\
\hline IRMOF-13 & cubic/catenation & $a=b=24.822, c=56.734$ & $\alpha=\beta=90, \gamma=120$ & 4.2/4.7/6.1/7.0/11.4 & 0.75 & 0.95 & 71.4 \\
\hline
\end{tabular}

${ }^{a}$ Obtained from the XRD crystal data (ref 30). ${ }^{b}$ Calculated with the Materials Studio package.

TABLE 2: LJ Potential Parameters for $\mathrm{CH}_{4}, \mathrm{H}_{2}$, and the IRMOFs Used in This Work

\begin{tabular}{lrrrrrr}
\hline LJ parameters & $\mathrm{CH}_{4}$ & \multicolumn{1}{l}{$\mathrm{H}_{2}$ H } & MOF_O & MOF_C & MOF_H & MOF_Zn \\
\hline$\sigma(\AA)$ & 3.73 & 2.72 & 3.12 & 3.43 & 2.57 & 2.46 \\
$\varepsilon / k_{\mathrm{B}}(\mathrm{K})$ & 148.0 & 10.00 & 30.19 & 52.84 & 22.14 & 62.40
\end{tabular}

and hydrogen in MOFs. ${ }^{23,34,36}$ For the IRMOFs studied here, an atomistic representation was used. For calculating the interactions between the adsorbate molecules and the atoms in the framework of the MOF materials, we adopted the universal force field (UFF) of Rappe et al., ${ }^{37}$ which has been successfully employed to depict the adsorption, ${ }^{35,38}$ diffusion, ${ }^{39,40}$ and separation $^{20,41}$ of several light gases and their mixtures in MOFs. The potential parameters used are listed in Table 2. In our simulations, all the LJ cross interaction parameters were determined by the Lorentz-Berthelot mixing rules.

To further confirm the reliability of the force fields adopted in this work, the adsorption isotherms of pure $\mathrm{CH}_{4}$ and $\mathrm{H}_{2}$ in IRMOF-1 (MOF-5) were simulated and compared with experimental data, as shown in Figure 2. The results show that the simulations enable excellent reproduction of the experimental adsorption isotherm of $\mathrm{CH}_{4}{ }^{17}$ up to ca. $3 \mathrm{MPa}$, whereas for $\mathrm{H}_{2}$, excellent agreement between simulation and experiment ${ }^{25}$ is also obtained up to $2 \mathrm{MPa}$; a similar conclusion has also been

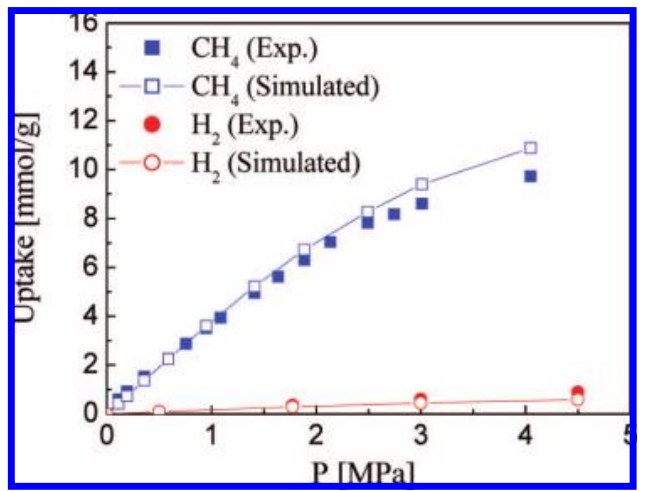

Figure 2. Comparison of simulated and experimental (refs 17 and 25) adsorption isotherms of $\mathrm{CH}_{4}$ and $\mathrm{H}_{2}$ in IRMOF-1 (MOF-5) at $298 \mathrm{~K}$.

obtained by Frost and Snurr. ${ }^{27}$ Therefore, the force fields adopted in this work are reliable to investigate the adsorption separation selectivity of $\mathrm{CH}_{4} / \mathrm{H}_{2}$ mixtures in IRMOFs with pressure up to $2 \mathrm{MPa}$.

2.3. Simulation Method. Grand canonical Monte Carlo (GCMC) simulations were employed to calculate the adsorption of pure components and their mixtures in all IRMOFs. Similar to previous works, ${ }^{20-23}$ all the IRMOFs were treated as rigid 


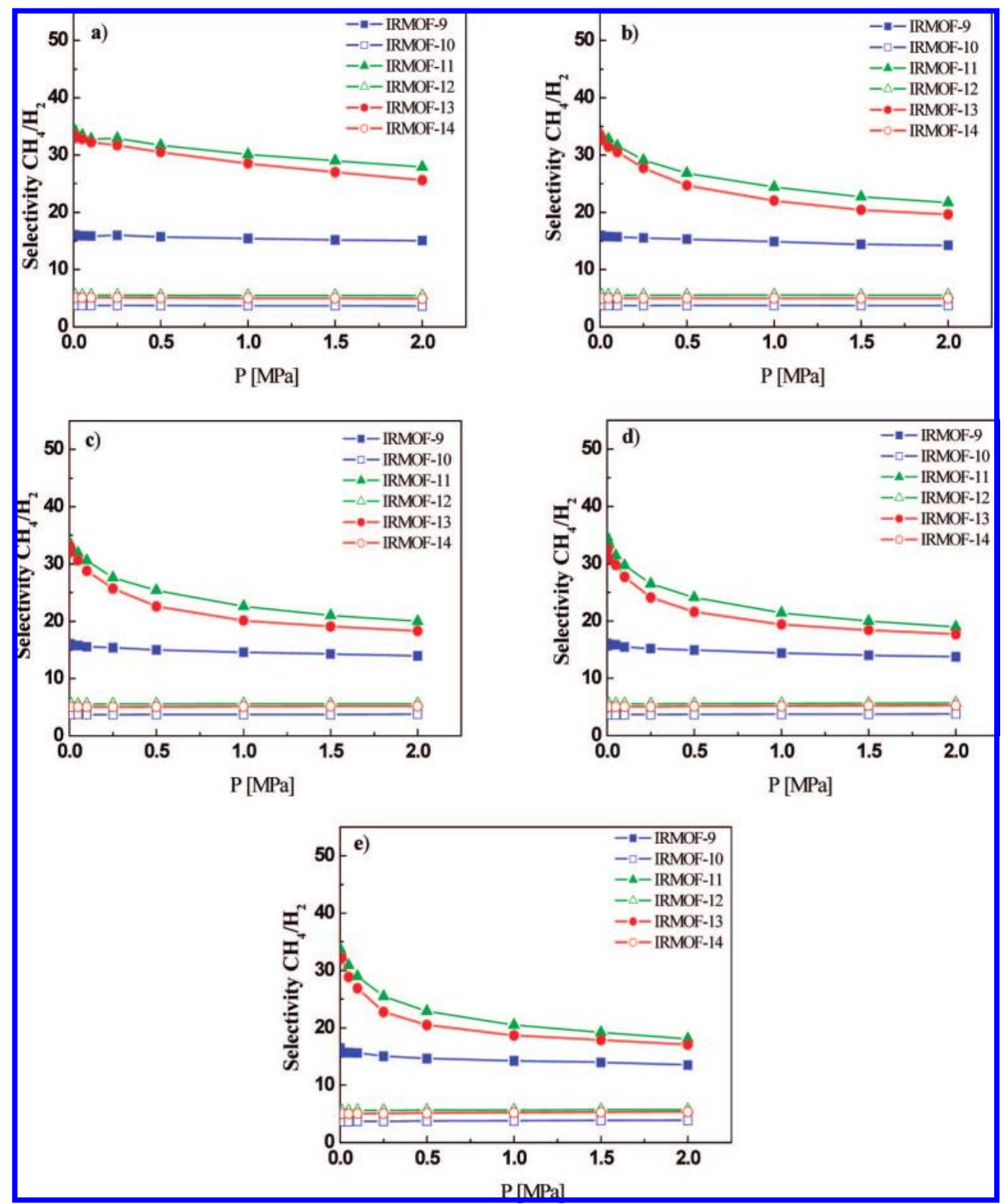

Figure 3. Selectivity for $\mathrm{CH}_{4}$ from binary mixtures of $\mathrm{CH}_{4} / \mathrm{H}_{2}$ with various gas compositions at $298 \mathrm{~K}$ : (a) $5 \% \mathrm{CH}_{4}$ and $95 \% \mathrm{H}_{2}$, (b) $30 \% \mathrm{CH}_{4}$ and $70 \% \mathrm{H}_{2}$, (c) $50 \% \mathrm{CH}_{4}$ and $50 \% \mathrm{H}_{2}$, (d) $70 \% \mathrm{CH}_{4}$ and $30 \% \mathrm{H}_{2}$, and (e) $95 \% \mathrm{CH}_{4}$ and $5 \% \mathrm{H}_{2}$.

frameworks, with atoms frozen at their crystallographic positions during simulations. A cutoff radius of $12.8 \AA$ was applied to the LJ interactions. To convert the experimental pressures to chemical potentials, which are required in the GCMC simulations, we used the Peng-Robinson equation of state. For each state point, GCMC simulation consisted of $1.5 \times 10^{7}$ steps, to guarantee equilibration, followed by $1.5 \times 10^{7}$ steps to sample the desired thermodynamic properties. To estimate the statistical uncertainty, the production phase of each state point was divided into 10 blocks and the standard deviation of the block average was calculated. The statistical uncertainties on the final results, including the ensemble averages of the number of adsorbate molecules in the simulation cell and the total potential energy, were estimated to be within $\pm 2 \%$. A detailed description of the simulation methods can be found in ref 42 .

\section{Results and Discussion}

In separation processes a good indication of the ability for separation is the selectivity of a porous material for different components in mixtures. The selectivity for component $\mathrm{A}$ relative to component B is defined by $S=\left(x_{\mathrm{A}} / x_{\mathrm{B}}\right)\left(y_{\mathrm{B}} / y_{\mathrm{A}}\right)$, where $x_{\mathrm{A}}$ and $x_{\mathrm{B}}$ are the mole fractions of components $\mathrm{A}$ and $\mathrm{B}$ in the adsorbed phase and $y_{\mathrm{A}}$ and $y_{\mathrm{B}}$ are the mole fractions of components $\mathrm{A}$ and $\mathrm{B}$ in the bulk phase, respectively. In this work, we first compared the adsorption selectivity of the six MOFs to reveal the effect of interpenetration, then studied the effect of mixture composition on selectivity, and finally carried out ideal adsorbed solution theory (IAST) calculations to check whether IAST is applicable to MOFs with interpenetration.

3.1. Adsorption Selectivity. As a first step, we performed molecular simulations to calculate the adsorption selectivity of methane from the binary mixtures of $\mathrm{CH}_{4} / \mathrm{H}_{2}$ in the three interpenetrated IRMOFs as well as their noninterpenetrated counterparts. The results for five different gas compositions at $298 \mathrm{~K}$ are shown in Figure 3 as a function of the bulk pressure up to $2.0 \mathrm{MPa}$.

Figure 3 shows the effect of interpenetration (catenation) on gas mixture separation is most pronounced at room temperature. The adsorption selectivities for $\mathrm{CH}_{4}$ in the IRMOFs (IRMOF9, IRMOF-11, and IRMOF-13) with interpenetration are much 


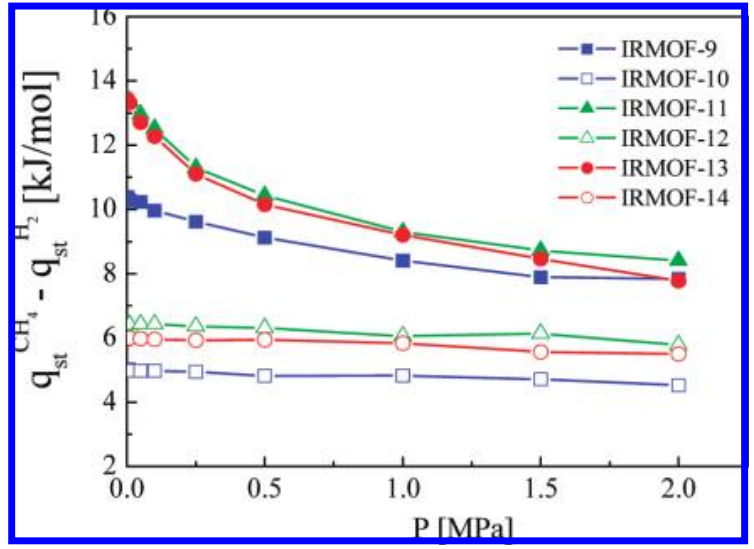

Figure 4. Differences of isosteric heats of adsorption between $\mathrm{CH}_{4}$ and $\mathrm{H}_{2}$ in the six IRMOFs as a function of pressure (only the parts contributed by the adsorbate/IRMOF framework interactions are given).

higher than those in their corresponding noninterpenetrated counterparts (IRMOF-10, IRMOF-12, and IRMOF-14, respectively), indicating that catenation can improve the adsorption selectivity for $\mathrm{CH}_{4} / \mathrm{H}_{2}$ system significantly. Separation of equimolar mixture of $\mathrm{CH}_{4} / \mathrm{H}_{2}$ has been performed in other porous materials, for example, at room temperature and moderate pressure, the selectivity of $\mathrm{CH}_{4}$ is 5.0 in MOF-5, ${ }^{21} 13.3$ in $\mathrm{Cu}-\mathrm{BTC},{ }^{21}$ (a highly porous MOF, BTC: benzene-1,3,5tricarboxylate) 8.0 in SAPO-34 membrane, ${ }^{43} 2.0$ in microporous SSF membrane, ${ }^{44}$ and 13.0 in carbon nanotubes. ${ }^{45}$ Obviously, Figure 3 demonstrates that IRMOF-9, IRMOF-11, and IRMOF13 show much larger selectivity than the above-mentioned materials, illustrating the generation of interpenetrated structures is a promising strategy to produce MOF materials for separation applications.

In addition, from Figure 3 we can see the pressure-dependent behavior of adsorption selectivity is much different in the two types of materials, i.e., the noninterpenetrated IRMOFs and their interpenetrated counterparts. For IRMOF-10, IRMOF-12, and IRMOF-14, the selectivities of methane are nearly pressureindependent for all the gas compositions within the pressure range studied. The reasons are that their crystal structures are very simple with large cubic pores, and up to $2.0 \mathrm{MPa}$ there is still much space in the pores of the materials; thus, the packing effect that favors the adsorption of hydrogen will only play a role at much higher pressures. As to IRMOF-9, IRMOF-11, and IRMOF-13, the adsorption selectivity curves contain two steps: a quick decrease at low pressures, followed by a slow decrease with further increasing pressure, and with increasing the gas compositions of $\mathrm{CH}_{4}$ this trend becomes more pronounced. This can be attributed to the facts that in the interpenetrated IRMOFs there are different types of pores (4 in IRMOF-9, 6 in IRMOF11 , and 5 in IRMOF-13) with much smaller sizes, leading to stronger confinement effects and the packing effects become evident at low pressures; the existence of small pores together with the heterogeneity in pore size results in a decrease of methane selectivity with increasing pressure. Similar behavior has also been observed in our previous work for the separation of $\mathrm{CH}_{4} / \mathrm{H}_{2}$ mixture in $\mathrm{Cu}-\mathrm{BTC}$, which has two kinds of small size pores. ${ }^{21}$

To understand the effect of interpenetration, we further analyzed the loading dependency of the adsorbate/IRMOF framework interactions for an equimolar mixture of $\mathrm{CH}_{4} / \mathrm{H}_{2}$ as shown in Figure 4, in which the interactions were represented by the isosteric heats of adsorption contributed from the part of the adsorbate/IRMOF framework interactions. Obviously, the differences of isosteric heats of adsorption between $\mathrm{CH}_{4}$ and $\mathrm{H}_{2}$ in the IRMOFs with interpenetration are much higher than those in their corresponding noninterpenetrated counterparts; this explains the much larger selectivity observed in the former. Also, the pressure-dependent behavior of the difference of isosteric heats of adsorption is similar to that of selectivity (Figure 3). For the noninterpenetrated IRMOFs, the adsorbate-adsorbent interactions slightly decrease in a similar extent with increasing pressure (loading) for both $\mathrm{CH}_{4}$ and $\mathrm{H}_{2}$ in the pressure range studied, resulting in the differences of isosteric heats of adsorption between $\mathrm{CH}_{4}$ and $\mathrm{H}_{2}$ being nearly unchanged. Again this can be attributed to the facts that the crystal structures of these noninterpenetrated IRMOFs are very simple with large cubic pores, and up to 2.0 MPa there is still much space in the pores of the material. For the interpenetrated IRMOFs, the behaviors are caused by the existence of various small pores of different sizes; the small pores and the heterogeneous nature in pore size result in a decrease of the differences of isosteric heats of adsorption with increasing loading (pressure).

As the structures of interpenetrated IRMOFs are somewhat more complicated, it is instructive to study the occupying situation of hydrogen and methane molecules in these IRMOFs in detail and to clarify the different separation selectivity regions in them. In this work the center of mass (COM) probability distributions of methane and hydrogen for equimolar mixture of $\mathrm{CH}_{4} / \mathrm{H}_{2}$ in the three interpenetrated IRMOFs at different pressures were examined. Figure 5 shows, as an example, these distributions in IRMOF-9.

As can be seen from Figure $5 \mathrm{a}-\mathrm{c}$ (here we only show the COM probability densities of methane for clarity), strongest adsorption for methane occurs in the small pores formed by the interpenetration of frameworks, the ones formed by two metal clusters and phenyl linkers, particularly in the corner area, where strongest overlap of the interactions from metal clusters and phenyl linkers occurs; with increasing pressure (loading), the areas formed by one metal cluster and a phenyl linker in another chain also adsorb methane strongly (Figure 5, parts b and c). This confirms that catenation can improve gas affinity. The COM probability densities of hydrogen are shown in Figure $5 \mathrm{~d}-\mathrm{f}$. It should be pointed out that here the densities are enlarged 100 times for visualization, and methane was omitted for clarity. Similar to methane, at low pressure, hydrogen is preferably to be adsorbed in the small pores formed by two metal clusters and phenyl linkers; however, with increasing pressure, hydrogen molecules seem to distribute more uniformly in the material (Figure 5, parts e and f), due to the presence of more methane molecules that occupied most the favorable adsorption sites. It seems the largest selectivity should occur in the small pores formed by interpenetration; however, it is difficult to get a clear picture from the COM figures shown in Figure 5. Therefore, we computed the local selectivity in the materials.

The selectivity distribution of methane for equimolar mixture of $\mathrm{CH}_{4} / \mathrm{H}_{2}$ in IRMOF-9 at $298 \mathrm{~K}$ and $2 \mathrm{MPa}$ is shown in Figure 6. The selectivity distribution is heterogeneous in the material, with highest selectivity occurring in the small pores formed by two metal clusters and phenyl linkers. In this region the selectivity ranges from 30 to 90 , much higher than the average value of 14 . The small pores formed by the linker-linker region also show high selectivity (around 20), with lowest selectivity in the center of the large pores (around 4). Figure 6 gives a clear picture on the selectivity distribution in the material, and it is expected that, with increasing pressure, the contribution of 


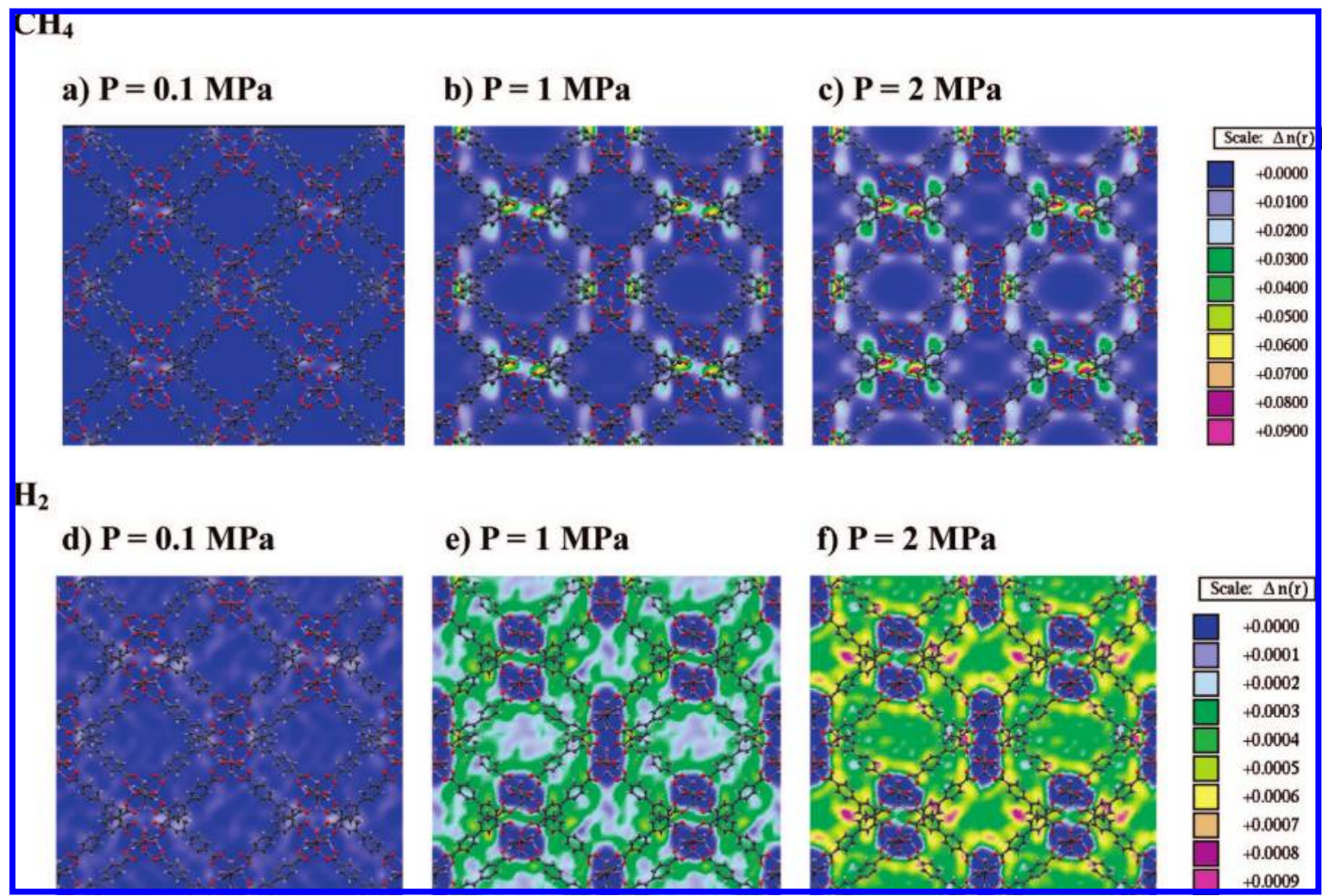

Figure 5. Contour plots of the COM probability densities of $\mathrm{CH}_{4}(\mathrm{a}-\mathrm{c})$ and $\mathrm{H}_{2}(\mathrm{~d}-\mathrm{f})$ in planes through the catenated area in IRMOF-9 at different pressures ( $\mathrm{Zn}$, blue; $\mathrm{O}$, red; $\mathrm{C}$, gray, and $\mathrm{H}$, white).

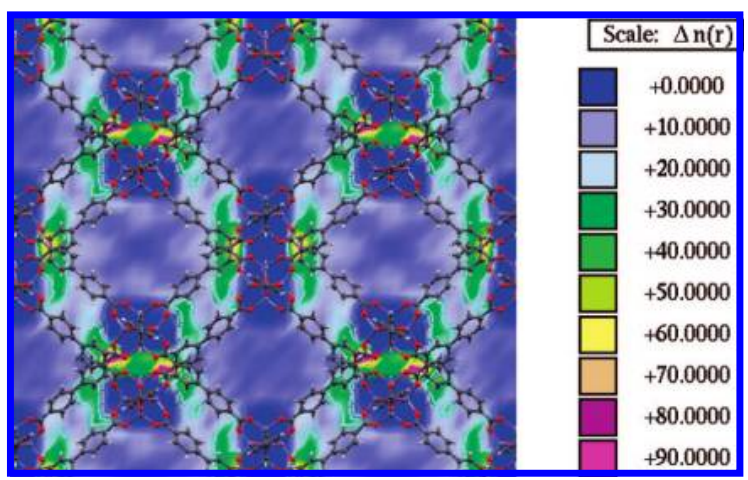

Figure 6. Contour plot of adsorption selectivities of $\mathrm{CH}_{4}$ for equimolar mixture of $\mathrm{CH}_{4} / \mathrm{H}_{2}$ at $2 \mathrm{MPa}$ and $298 \mathrm{~K}$ in planes through the catenated area in IRMOF-9 (Zn, blue; O, red; C, gray, and $\mathrm{H}$, white).

the small pores formed by the linker-linker region will become more important. The selectivity distribution plot for $1 \mathrm{MPa}$ is very similar to the one for $2 \mathrm{MPa}$. As to $0.1 \mathrm{MPa}$, since the number of molecules in the system is too small to reliably estimate the local selectivity, the selectivity distribution figure was not calculated.

3.2. Effect of Composition on Selectivity. For practical applications, it is useful to know how the adsorption selectivity varies with the gas mixture composition. Figure 7 gives the selectivities of methane for $\mathrm{CH}_{4} / \mathrm{H}_{2}$ mixtures at five compositions, as a function of pressure. Figure 7 shows that the selectivity does not strongly depend on gas mixture composition for the three noninterpenetrated IRMOFs within the pressure range studied. For the interpenetrated frameworks, however, the mixture composition does affect the selectivity. This can be attributed to the differences in crystal structures of these two types of materials. The three noninterpenetrated IRMOFs have very simple crystal structures, and the pores are rather large compared to the adsorbates studied. Within the pressure range considered, there is still much free volume in the pores of these materials for all gas mixture compositions, whereas for the interpenetrated IRMOFs the situation is different as they have various smaller pores of different sizes, resulting in more complicated structures. Therefore, the selectivity is more sensitive to both pressure and composition. As can be seen from Figure 7, the selectivities of methane at various compositions are identical at very low pressure, whereas with increasing pressure, methane selectivity decreases with increasing the bulk molar fraction of methane. The reasons for these phenomena are that in the infinite dilution region, the selectivity of a mixture depends mainly on the interactions of the adsorbent with the adsorbate, whereas with the increasing of pressure, the molecules have to compete for space and confinement effects become evident; in this case, pore size, topology, as well as heterogeneity in structure play more important roles, and their effects on selectivity depend on the composition of the mixtures in the pores. Although the mixture composition affects the selectivity in the three interpenetrated IRMOFs, within the entire composition range they show much larger methane selectivity than their noninterpenetrated counterparts. Therefore, this work demonstrates that the creation of interpenetrated frameworks is a promising strategy to develop new MOFs with enhanced adsorption separation selectivity.

3.3. IAST Prediction. It has been commonly recognized that $\mathrm{IAST}^{46}$ can give good predictions of gas mixture adsorption in many zeolites, ${ }^{47,48}$ and in our previous work we have demonstrated it is applicable for depicting the $\mathrm{CH}_{4} / \mathrm{H}_{2}$ adsorption in noninterpenetrated IRMOF-1 and $\mathrm{Cu}-\mathrm{BTC} .{ }^{21}$ IAST calculations were performed to check whether this is also the case for interpenetrated MOFs. The calculated adsorption selectivities 


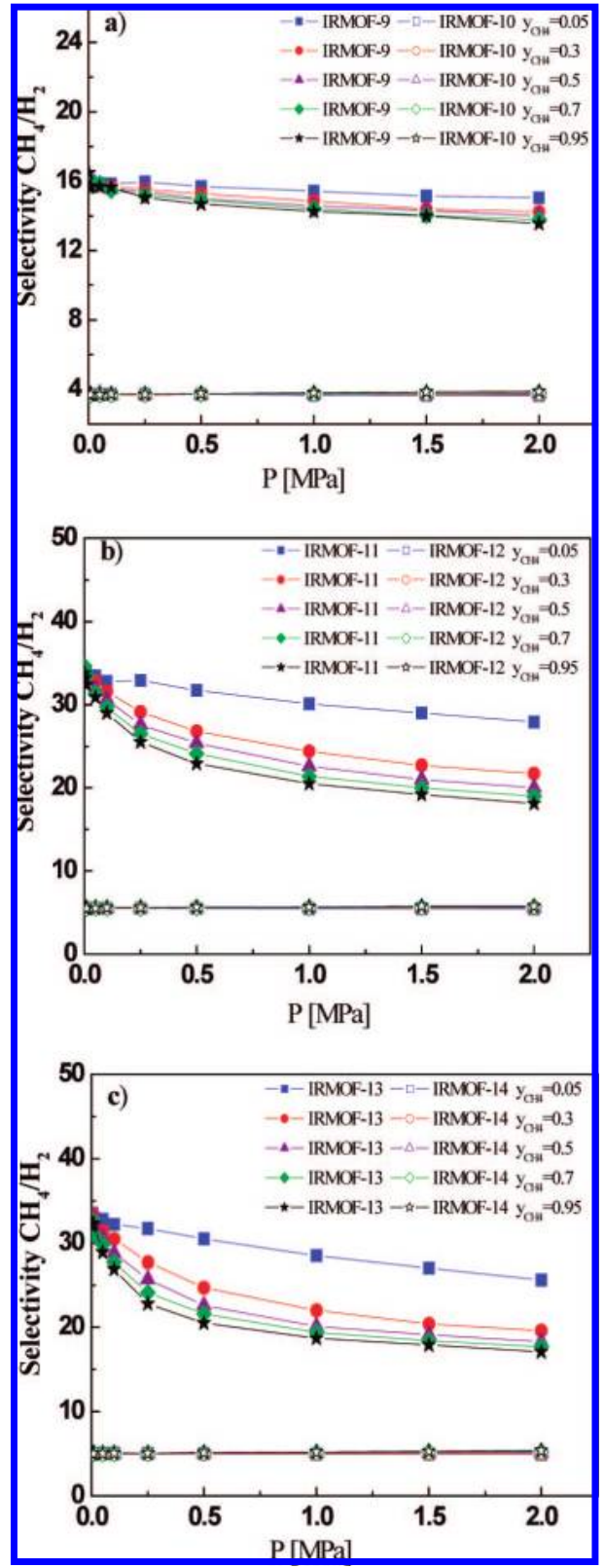

Figure 7. $\mathrm{CH}_{4}$ selectivities from binary mixtures of $\mathrm{CH}_{4} / \mathrm{H}_{2}$ as a function of gas composition and pressure at $298 \mathrm{~K}$ in (a) IRMOF-9 and IRMOF-10, (b) IRMOF-11 and IRMOF-12, and (c) IRMOF-13 and IRMOF-14.

of methane at different compositions with GCMC and IAST in IRMOF-9 and IRMOF-11 are shown in Figure 8 as an example. In all the cases, good agreement between GCMC simulation and IAST calculation was obtained, indicating that IAST is applicable to predict the adsorption behavior of $\mathrm{CH}_{4} / \mathrm{H}_{2}$ mixture in the interpenetrated IRMOFs studied.

\section{Conclusions}

This work shows that, due to the additional small pores and adsorption sites formed by the interpenetration of frameworks, the adsorption selectivity of $\mathrm{CH}_{4} / \mathrm{H}_{2}$ mixtures is greatly enhanced in the three interpenetrated IRMOFs compared with their noninterpenetrated counterparts. In the interpenetrated MOFs, because of the existence of various small pores of different sizes, methane selectivity shows more complex behavior, and the selectivity differs largely in the different areas of the pores. In addition, this work shows IAST is likely to be applicable to

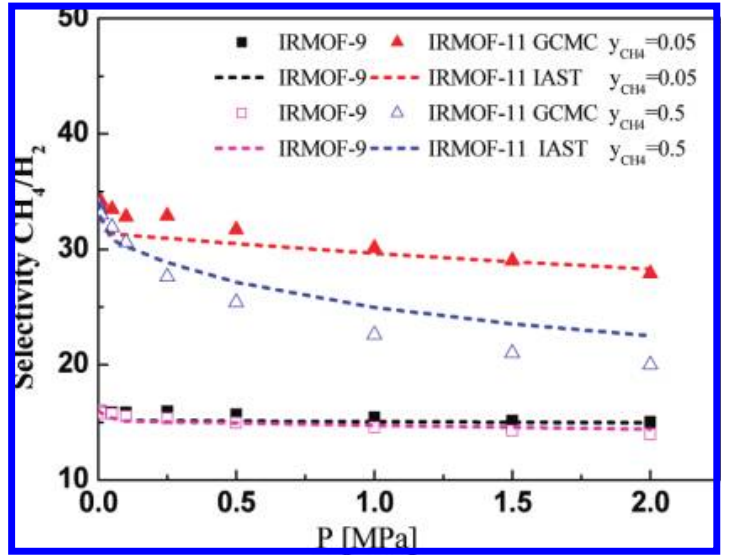

Figure 8. Comparison of IAST and GCMC for $\mathrm{CH}_{4}$ selectivity from binary mixtures of $\mathrm{CH}_{4} / \mathrm{H}_{2}$ as a function of gas composition and pressure in IRMOF-9 and IRMOF-11 at $298 \mathrm{~K}$.

interpenetrated MOFs with complex structures. On the basis of the results obtained, it may be concluded that the creation of interpenetrated frameworks is a promising strategy to develop MOFs with high separation performance.

At the moment, there are no experimental data to check our results; it would be interesting to see whether experiments can confirm our observations in the future. Also, it would be an interesting topic to study the performance of membranes based on these MOFs, both experimentally and theoretically.

Acknowledgment. The financial support of the NSFC (Nos. 20725622, 20706002) and the Dutch STW/CW Separation Technology program (700.56.655-DPC.6243) are greatly appreciated.

\section{References and Notes} 4670

(1) Rowsell, J. L. C.; Yaghi, O. M. Angew. Chem., Int. Ed. 2005, 44,

(2) Férey, G. Chem. Soc. Rev. 2008, 37, 191.

(3) Mueller, U.; Schubert, M.; Teich, F.; Puetter, H.; Schierle-Arndt, K.; Pastré, J. J. Mater. Chem. 2006, 16, 626.

(4) Kubota, Y.; Takata, M.; Matsuda, R.; Kitaura, R.; Kitagawa, S.; Kato, K.; Sakata, M.; Kobayashi, T. C. Angew. Chem., Int. Ed. 2005, 44, 920.

(5) Kayes, S. S.; Long, J. R. J. Am. Chem. Soc. 2008, 130, 806.

(6) Kesanli, B.; Cui, Y.; Smith, M. R.; Bittner, E. W.; Bockrath, B. C.; Lin, W. Angew. Chem., Int. Ed. 2005, 44, 72.

(7) Chen, B.; Ma, S.; Hurtado, E. J.; Lobkovsky, E. B.; Zhou, H. C. Inorg. Chem. 2007, 46, 8490 .

(8) Ma, S.; Sun, D.; Ambrogio, M.; Fillinger, J. A.; Parkin, S.; Zhou, H. C. J. Am. Chem. Soc. 2007, 129, 1858.

(9) Rowsell, J. L. C.; Yaghi, O. M. J. Am. Chem. Soc. 2006, 128, 1304.

(10) Chen, B.; Ma, S.; Zapata, F.; Lobkovsky, E. B.; Yang, J. Inorg. Chem. 2006, 45, 5718.

(11) Chen, B.; Liang, C.; Yang, J.; Contreras, D. S.; Clancy, Y. L.; Lobkovsky, E. B.; Yaghi, O. M.; Dai, S. Angew. Chem., Int. Ed. 2006, 45, 1390

(12) Bastin, L.; Bárcia, P. S.; Hurtado, E. J.; Silva, J. A. C.; Rodrigues, A. E.; Chen, B. J. Phvs. Chem. C 2008, 112, 1575.

(13) Bárcia, P. S.; Zapata, F.; Silva, J. A. C.; Rodrigues, A. E.; Chen, B. J. Phys. Chem. B 2007, 111, 6101.

(14) Fost, H.; Düren, T.; Snurr, R. Q. J. Phvs. Chem. B 2006, 110, 9565.

(15) Walton, K. S.; Millward, A. R.; Dubbeldam, D.; Frost, H.; Low,

J. J.; Yaghi, O. M.; Snurr, R. Q. J. Am. Chem. Soc. 2008, 130, 406.

(16) Ramsahye, N. A.; Maurin, G.; Bourrelly, S.; Llewellyn, P. L.; Serre, C.; Loiseau, T.; Devic, T.; Ferey, G. J. Phvs. Chem. C 2008, 112, 514.

(17) Düren, T.; Sarkisov, L.; Yaghi, O. M.; Snurr, R. Q. Langmuir 2004, 20,2683 .

(18) Liu, J.; Culp, J. T.; Natesakhawat, S.; Bockrath, B. C.; Zande, B.; Sankar, S. G.; Garberoglio, G.; Johnson, J. K. J. Phys. Chem. C 2007, 111, 9305.

(19) Yang, Q.; Xue, C.; Zhong, C.; Chen, J. AIChE J. 2007, 53, 2832.

(20) Keskin, S.; Sholl, D. S. J. Phys. Chem. C 2007, 111, 14055.

(21) Yang, Q.; Zhong, C. J. Phvs. Chem. B 2006, 110, 17776. 
(22) Yang, Q.; Zhong, C. ChemPhvsChem 2006, 7, 1417.

(23) Düren, T.; Snurr, R. Q. J. Phvs. Chem. B 2004, 108, 15703.

(24) Latroche, M.; Surblé, S.; Serre, C.; Mellot-Draznieks, C.; Llewellyn,

P. L.; Lee, J. H.; Chang, J. S.; Jhung, S. H.; Férey, G. Angew. Chem.. Int. Ed. 2006, 45, 8227.

(25) Li, Y.; Yang, R. T. J. Am. Chem. Soc. 2006, 128, 8136.

(26) Kaye, S. S.; Dailly, A.; Yaghi, O. M.; Long, J. R. J. Am. Chem. Soc. 2007, 129, 14176.

(27) Frost, H.; Snurr, R. Q. J. Phys. Chem. C 2007, 111, 18794.

(28) Dubbeldam, D.; Frost, H.; Walton, K. S.; Snurr, R. Q. Fluid Phase Equilib. 2007, 261, 152 .

(29) Yang, Q.; Zhong, C. J. Phvs. Chem. C 2008, 112, 1562.

(30) Eddaoudi, M.; Kim, J.; Rosi, N.; Vodak, D.; Wachter, J.; O'Keeffe, M.; Yaghi, O. M. Science 2002, 295, 469.

(31) Mitchell, M. C.; Gallo, M.; Nenoff, T. M. J. Chem. Phys. 2004, 121,1910 .

(32) Materials Studio, 3.0 V; Accelrys Inc.: San Diego, CA, 2003.

(33) Martin, M. G.; Siepmann, J. I. J. Phvs. Chem. B 1998, 102, 2569.

(34) Yang, Q.; Zhong, C. J. Phvs. Chem. B 2005, 109, 11862.

(35) Garberoglio, G.; Skoulidas, A. I.; Johnson, J. K. J. Phvs. Chem. B 2005, 111, 13094

(36) Surblé, S.; Millange, F.; Serre, C.; Düren, T.; Latroche, M.; Bourrelly, S.; Llewellyn, P. L.; Férey, G. J.Am. Chem. Soc. 2006, 128, 14889.
(37) Rappé, A. K.; Casewit, C. J.; Colwell, K. S.; Goddard, W. A., III; Skiff, W. M. J. Am. Chem. Soc. 1992, 114, 10024.

(38) Krungleviciute, V.; Lask, K.; Heroux, L.; Migone, A. D.; Lee, J.Y.; Li, J.; Skoulidas, A. Langmuir 2007, 23, 3106.

(39) Skoulidas, A. I.; Sholl, D. S. J. Phvs. Chem. B 2005, 109, 15760.

(40) Skoulidas, A. I. J. Am. Chem. Soc. 2004, 126, 1356.

(41) Babarao, R.; Hu, Z.; Jiang, J.; Chempath, S.; Sandler, S. I. Langmuir 2007, 23, 659 .

(42) Frenkel, D.; Smit, B. Understanding Molecular Simulations: From Algorithms to Applications, 2nd ed.; Academic Press: San Diego, CA, 2002.

(43) Poshysta, J. C.; Tuan, V. A.; Pape, E. A.; Noble, R. D.; Falconer, J. L. AIChE J. 2000, 46, 779 .

(44) Vieira-Linhares, A. M.; Seaton, N. A. Chem. Eng. Sci. 2003, 58, 4129 .

(45) Chen, H. B.; Sholl, D. S. J. Membr. Sci. 2006, 269, 152

(46) Myers, A. L.; Prausnitz, J. M. AIChE J. 1965, 11, 121.

(47) Goj, A.; Sholl, D. S.; Akten, E. D.; Kohen, D. J. Phvs. Chem. 2002, $106,8367$.

(48) Challa, S. R.; Sholl, D. S.; Johnson, J. K. J. Chem. Phvs. 2002, 116,814

JP802343N 